\title{
Analysis of abnormal epithelial lesions in cervical Pap smears in Mid-Western Nepal
}

\author{
Ranabhat $\mathrm{SK}^{1}$, Shrestha $\mathrm{R}^{1}$, Tiwari $\mathrm{M}^{1}$ \\ ${ }^{1}$ Department of Pathology, Chitwan Medical College, Chitwan, Nepal.
}

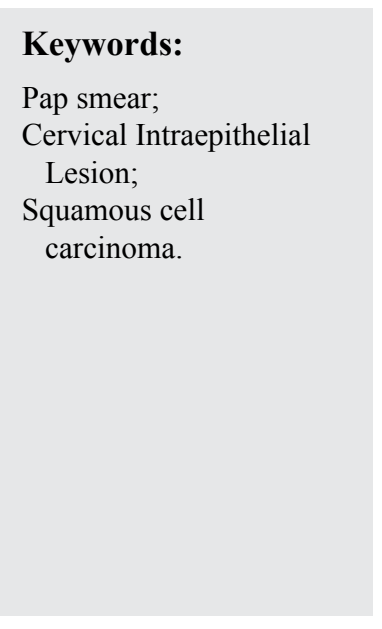

\begin{abstract}
Background: Like in other developing countries, cancer of cervix is one of the most common malignancies in women in Nepal. Most women never undergo a cervical Pap smear screening. The objective of this study is to determine the prevalence of abnormal cervical epithelial lesions.

Materials and Methods: This was a retrospective study of 880 conventional cervical Pap smears reported from the Department of Pathology, Chitwan Medical College in Chitwan, Nepal. The time period was from June 2009 to November 2010.

Results: In this study, High-grade Squamous Intraepithelial Lesion was the most common with 6 cases (40\%), followed by Low-grade Squamous Intraepithelial Lesion with 3 cases (20\%), then Atypical Squamous Epithelial Cells of Undetermined Significance, and atypical Glandular Cells and Squamous cell carcinoma with 2 cases each $(13.3 \%)$. Eighty per cent of all the abnormal epithelial lesions were found in women above the age of 40 years.
\end{abstract}

Conclusion: At least one Pap screening test of the cervix of all women between the ages of 40-50 years is recommended.

\section{INTRODUCTION}

World-wide data shows that cervical cancer is the second most common cancer in women, comprising of approximately $12 \%$ of all cancers, and being the most common in developing countries. ${ }^{1}$ Globally, 500,000 new cases are diagnosed annually and 280,000 women die of the disease. $^{2}$

Invasive cervical malignancy is preceded by premalignant

\section{Correspondence:}

Dr. Sabin K Ranabhat, MD

Department of Pathology, Chitwan Medical College, Nepal

E-mail:rbhatsabin@yahoo.com cervical epithelial lesions of different grades which are termed as cervical intraepithelial neoplasia (CIN). According to Bethesda system, preinvasive cervical lesions are classified into two groups: Low-grade Squamous Intraepithelial Lesion (LSIL) and High-grade Squamous Intraepithelial Lesion (HSIL). ${ }^{3}$ Cancer of the cervix can be prevented by intercepting it at the preinvasive stage. The role of the Pap smear as a cancer screening tool for the cervix has been substantiated by several studies in the last 50 years ${ }^{4,5}$ and the method has resulted in a decrease in the incidence and mortality rates of cervical cancer in the developed world. ${ }^{6,7}$ The success of Pap smear cytology in North America, Europe and Scandinavian countries 
has been the result of organized Pap smear screening programs. Nationwide screening programs were introduced in different countries and they demonstrated the efficacy of cytology screening programs. The International Agency for Research on Cancer (IARC) assessed the potential reduction in cumulative incidence rates for cancer of cervix with different frequencies. Assuming that the screening sensitivity is $100 \%$ and $80 \%$ of the women were screened, all women aged 35-64 years of age had a 93\% annual decrease in the incidence of the disease. The incidence rate of the 5 and 10 year annual screening resulted in a reduction of $84 \%$ and $64 \%$ respectively. Based on this data, developed nations recommend a frequent Pap screening program. The mortality rate of cervical cancer can be significantly reduced if a woman is screened once when she is between the ages of $40-45$ years. $^{8}$

According to a regional study, cancer of cervix makes up about $85 \%$ of all gynecologic malignancies in Nepal. ${ }^{9}$ There is a need for well-organized screening and educational programs for the control and prevention of cervical cancer in this country. The objective of this study was to determine the prevalence of abnormal cervical epithelial lesions.

\section{MATERIALS AND METHODS}

This was a retrospective study of all cervical Pap smear cases reported at the Department of Pathology, Chitwan Medical College Teaching Hospital for a period of 17 months from June 15, 2009 to November 16, 2010. All of the findings were recorded and classified according to the 2001 Bethesda System reporting Pap smear cytology. The data were analyzed using Microsoft Excel 2003 for windows.

\section{RESULTS}

A total of 928 cases were reported during the above mentioned period. Twenty-eight $(3.12 \%)$ smears were found to be unsatisfactory for evaluation and in 21 patients $(2.26 \%)$ the age was not known. These cases were excluded from the study. A total of 880 cases were analyzed (Table 1 and 2). The age of the patients ranged from 20 to 81 years with an average age of 36.7 years. Most of the patients were

Table 1: Age-wise distribution of total number of patients

\begin{tabular}{ccc}
\hline Age-group & Number of patients & Percentage \\
\hline$<20$ & 0 & 00.00 \\
$20-29$ & 207 & $23.52 \%$ \\
$\mathbf{3 0 - 3 9}$ & 354 & $40.23 \%$ \\
$\mathbf{4 0 - 4 9}$ & 216 & $24.55 \%$ \\
$\mathbf{5 0 - 5 9}$ & 74 & $08.41 \%$ \\
$\mathbf{6 0 - 6 9}$ & 21 & $02.38 \%$ \\
$>\mathbf{7 0}$ & 08 & $00.91 \%$ \\
\hline Total & 880 & $100.00 \%$ \\
\hline
\end{tabular}

Table 2: Findings of Pap smear cytology

\begin{tabular}{cllc}
\hline S.N. & \multicolumn{1}{c}{ Diagnosis } & Number of cases & Percentage \\
\hline 1 & ASC-US & 02 & 00.23 \\
2 & AGC & 02 & 00.23 \\
3 & LSIL & 03 & 00.34 \\
4 & HSIL & 06 & 00.68 \\
5 & Squamous cell carcinoma & 02 & 00.23 \\
6 & NIL & 865 & 98.29 \\
& Total & 880 & 100.00 \\
\hline \multirow{2}{*}{ *NIL: Negative for Intraepithelial Lesion or Malignancy }
\end{tabular}

in the age-group of 30-39 years.

The Negative for Intraepithelial Lesion or malignancy (NIL) category has the following findings: nonspecific inflammation 229 cases (26\%), reactive cellular changes 22 cases $(2.5 \%)$, Candidiasis 9 cases $(1 \%)$, Trichomoniasis 4 cases $(0.45 \%)$, Bacterial vaginosis 67 cases $(7.6 \%)$ and Herpes simplex virus infection 3 cases $(0.34 \%)$. Specific infections were detected in 83 cases $(9.39 \%)$. Eighty per cent of all the epithelial abnormalities were found in the age group $>40$ years of age. The average age of patients for all the epithelial abnormalities was 49 years.

\section{DISCUSSION}

The incidence of cervical cancer has decreased more than $50 \%$ in the past 30 years because of widespread screening with cervical cytology. In 1975, the rate was 14.8 per 100,000 women in the United States and by 2006, it had been reduced to 6.5 per 100,000 women. Mortality from the disease has undergone a similar decrease. ${ }^{10-12}$ Considering the efficacy of Pap smear cytology in preventing cervical cancer, it is advocated that it should be initiated in all women at the age of 21 years. ${ }^{13}$ Women of Nepal are not receiving the benefit of Pap smear testing.

The average age of patients in this study was 37 years. About $76 \%$ of the total cases are above the age of 30 years. This study reveals that Pap smear cytology is delayed by many years in the majority of women of this country. The physicians or healthcare professionals are not requesting Pap smear testing and not educating people about the benefits of the Pap smear test. ${ }^{14}$ More education programs should be created to increase the awareness of the benefit of cervical Pap smears.

In this study, there were 15 cases of abnormal epithelial lesions $(1.7 \%)$. The percentage of epithelial abnormalities is $2.3 \%$ to $6.6 \%$, in the US, from $1.6 \%$ to $7.9 \%$ in the Middle East, and 1.87 to $5.9 \%$ in India. ${ }^{15}$

The low incidence (2 cases) of Atypical Squamous Epithelial Cells of Undetermined Significance (ASC-US) in this study is possibly due to this lesion being commonly 
found in a younger age group. A similar finding was seen in Saudi Arabia. ${ }^{16}$

Another reason for the overall low prevalence of abnormal epithelial lesions in this study is due to the small sample size. The study in Maternity Hospital, Kathmandu, Nepal has also found a low prevalence of abnormal epithelial lesions. ${ }^{17}$ A large scale study encompassing women from different strata and age groups is required to determine the actual incidence of abnormal cervical epithelial lesions in Nepal.

In a study carried out in the Tribhuvan University Teaching Hospital, carcinoma of cervix was the third most common of all cancer cases. ${ }^{18}$ The study in a cancer hospital in Chitwan, Nepal carcinoma of cervix was the most common gynecologic malignancy. ${ }^{9}$ The HSIL was reported as high as $3.7 \%$ in Zimbabwe and China. ${ }^{19,20}$ Our study also showed that the HSIL is the most common of all the abnormal epithelial lesions.

This study shows that the incidence of high grade epithelial lesion increases with advancing age. Cancer of the uterine cervix should get priority in terms of control programs through mass screening in Nepal. ${ }^{21}$

In this study, $80 \%$ of all abnormal epithelial lesions were found in the age-group above 40 years as about $80 \%$ of the patients were above the age of 30 years (Table 3). A study done in India has found that $51.5 \%$ of SIL cases and $75.3 \%$ of cancer cases were detected in women above 40 years of age. ${ }^{22}$ Based on our findings, and considering the paucity of resources in Nepal, it is proposed that women beyond 40 years be screened at least once in their lifetime to detect abnormal epithelial lesions. According to WHO recommendations (1986), screening at 45 years of age is the most correct approach, which could detect approximately $20 \%$ of total cervical cancers. ${ }^{2}$ The American Cancer control Program and the IARC have suggested similar or slightly modified screening programs. ${ }^{23}$

\section{CONCLUSION}

Cervical cancer is one of the most common malignancies in the women of Nepal. Pap smear cytology is a useful screening tool to detect pre-invasive cervical epithelial lesions. Based on the findings of this study we recommend at least a single life-time Pap screening cytology of the uterine cervix of all the women aged 40 to 50 years.

\section{REFERENCES}

1. Ferlay J, Bray F, Pisani P, Parkin DM. GLOBOCAN 2002 Cancer Incidence, Mortality and Prevalence Worldwide, IARC Press, Lyon; 2004

2. The World Health Report, 1995. Bridging the gaps. Geneva: World Health Organization; 1995.

3. Solomon D, Davey D, Kurman R. The forum group members. The Bethesda 2001 workshop. The 2001 Bethesda system: terminology for reporting results of cervical cytology. JAMA 2002;287:2114-9.

4. Miller AB, Chamberlain J, Day NE, Hakama M, Prorok PC. Report on a workshop of the UICC project on evaluation of screening for cancer. Int J Cancer 1990;46:761-9.

5. Walton RJ. The task fore on cervical cancer screening programs. Can Med Assoc J 1976;114:981.

6. Hakama M, Rasanen-Virtanen U. Effect of a mass screening program on the risk of cervical cancer. Am J Epidemiol 1976;103:512-7.

7. Lyyry E, Day NE, Hakama M. Trends in mortality from cervical cancer in the Nordic countries: association with organized screening programs. Lancet 1987;1:1247-9.

8. Juneja A, Sehgal A, Sharma S, Pandey A: Cervical cancer screening in India: strategies revisited. Indian J of Medical Sciences 2007;61:347.

9. Pradhan M, Dhakal HP, Pun CB, Pradhan S, Dangal G: Gynecological malignancy in BPKMCH, Bharatpur: a retrospective analysis of 321 cases. JNMA 2001;40:108-11.

10. Herrero R. Epidemiology of cervical cancer. J Natl Cancer Inst Monogr 1996;21:1-6.

11. Eddy DM. Screening for cervical cancer. Ann Intern Med 1990;113:214-26.

12. Van der Graaf Y, Klinkhamer PJ, Vooijs GP. Effect of population screening for cancer of the uterine cervix in Nijmegen, The Netherlands. Prev Med 1986;15:582-90.

13. ACOG Practice Bulletin. Clinical management guidelines for obstetrician-gynaecologists; 2009.

14. Gamarra CJ, Paz EP, Griep RH: Knowledge, attitudes and practice related to Papanicolaou smear test among Argentina's women. Rev Saude Publica 2005;39:2.

15. Mulay K, Swain M, Patra S, Gowrishankar S. Comparative study of cervical smears in an Urban Hospital in India and a populationbased screening program in Mauritius. Indian J Pathol Microbiol 2009;52:34-7.

Table 3: Findings of Pap smear cytology

\begin{tabular}{|c|c|c|c|c|c|c|}
\hline \multirow{2}{*}{$\begin{array}{l}\text { Age-group } \\
\text { (years) }\end{array}$} & \multicolumn{5}{|c|}{ Diagnosis } & \multirow{2}{*}{ Percentage } \\
\hline & ASC-US & AGC & LSIL & HSIL & Carcinoma & \\
\hline$<30$ & 0 & 0 & 0 & 0 & 0 & 00.00 \\
\hline $30-39$ & 0 & 2 & 0 & 1 & 0 & 20.00 \\
\hline $40-49$ & 1 & 0 & 2 & 1 & 1 & 33.30 \\
\hline $50-59$ & 1 & 0 & 1 & 1 & 0 & 20.00 \\
\hline$>60$ & 0 & 0 & 0 & 3 & 1 & 26.70 \\
\hline Total $(n=15)$ & $2(13.3 \%)$ & $2(13.3 \%)$ & $3(20 \%)$ & $6(40 \%)$ & $2(13.3 \%)$ & 100.00 \\
\hline
\end{tabular}


16. Abdullah LS. Pattern of abnormal pap smears in developing countries: A report from a large referral hospital in Saudi Arabia using the revised 2001 Bethesda system. Ann Saudi Med 2007;27:268-72.

17. Dhaubhadel P, Vaidya A, Choudhary P. Early detection of precursors of cervical cancer with cervical cytology and visual inspection of cervix with Acetic acid. J Nepal Med Assoc 2008;47:71-6.

18. Shrestha HG, Dali S, Pradhan M. Present cancer status in TU Teaching Hospital, Nepal. J Soc Surg Nep 1992;2:16-23.

19. Tuncer ZS, Basaran M, Sezgin Y, Firat P, Ocan Kuzey G. Clinical results of a split sample liquid based cytology (Thin Prep) study of 4,322 patients in a Turkish institution. Eur J Gynaecol Oncol 2005;26:646-8.
20. Tbistle PJ, Chirenje ZM. Cervical cancer screening in a rural population of Zimbabwe. Cent Afr J Med 1997;43:246-51

21. Juneja A, Sehgal A, Sharma S, Pandey A. Cervical cancer screening in India: strategies revisited. Indian J Med Sci 2007;61:34-47.

22. Misra S, Srivastava S, Singh U, Srivastava AN. Risk actors and strategies for control of carcinoma cervix in India: Hospital based cytological screening experience of 35 years. Indian $\mathrm{J}$ Cancer 2009;46:155-9.

23. Alliance for cervical cancer prevention (ACCP): Planning and implementing cervical cancer prevention and control programs: A manual for managers. Seattle: ACCP; 2004. 